\title{
An industry survey on litter management and re-use practices of Australian meat chicken growers
}

\author{
C.-M. Pepper ${ }^{A, *}$ (i) and M. W. Dunlop ${ }^{A}$ (i)
}

For full list of author affiliations and declarations see end of paper

*Correspondence to:

C.-M. Pepper

Department of Agriculture and Fisheries, Queensland Government, 203 Tor Street Toowoomba, QId 4350, Australia

Email: clairemarie.pepper@daf.qld.gov.au

\section{Handling Editor:}

Stephen Walkden-Brown

Received: 22 April 2021

Accepted: 8 November 2021

Published: 21 December 202।

Cite this:

Pepper C-M and Dunlop MW (202I)

Animal Production Science

doi: I0.107|/AN2 222

(C) 2021 The Author(s) (or their employers(s)) and The State of Queensland (through the Department of Agriculture and Fisheries). Published by CSIRO Publishing. This is an open access article distributed under the Creative Commons AttributionNonCommercial-NoDerivatives 4.0 International License (CC BY-NC-ND).

OPEN ACCESS

\begin{abstract}
Litter management is important when rearing meat chickens because litter conditions can affect production as well as chicken health and wellbeing. An industry survey was conducted to gather information from Australian meat chicken growers and integrators about their litter management practices, providing an opportunity to share their knowledge, experiences and perceptions about litter re-use and litter turning. This information was essential for researchers investigating litter management practices because it provided a better understanding about litter preparation and shed configuration to ensure that representative and timely data could be collected. Eighty-four survey responses were received from all major growing regions across Australia. The survey closely reflected the proportions of conventional and free-range production systems of Australian chicken meat industry, with approximately $21 \%$ of survey responses representing free range and $80 \%$ representing conventional barn housing. Concerning litter management practices, the survey showed that litter re-use is limited (32\% of responses), but litter turning is a widespread practice ( $89 \%$ of responses). Litter turning is used to reduce the occurrence of caked litter and to keep litter 'working'. Maintaining 'dry and friable' litter has been shown to reduce the risk of health issues and allows chickens to display behaviours, such as dustbathing, which are believed to be associated with improved welfare. Comments from the survey indicated that litter turning alone does not achieve dry and friable litter, and that proactive ventilation, heater and drinker management are essential. Growers also explained that litter turning is not without its challenges, and can potentially contribute to spikes of dust, ammonia and/or odour. They also expressed concerns relating to operating machinery in poultry houses, particularly when there is high liveweight density. When growers were asked about litter re-use, several reported that it has benefits in reducing production costs and improving moisture holding capacity, but concerns were also expressed about risks relating to ammonia, litter beetle control and disease transmission. Researchers will be able to use these survey results to gain an insight into practices, perceptions, constraints, and challenges relating to the Australian chicken meat industry and ensure that future research relating to litter management reflects local conditions and practices.
\end{abstract}

Keywords: broiler, industry survey, litter management, litter re-use, litter tilling, litter turning, poultry, poultry litter.

\section{Introduction}

Good litter conditions are one of the key requirements in meat chicken rearing to ensure optimal production outcomes. In recent years, expectations on litter conditions have increased, with the minimum standard requiring litter to be of good quality, have minimal risk of being contaminated with toxic agents, and managed to avoid excessive caking, dustiness, wetness, or ammonia concentrations that may affect the welfare of the chickens (CSIRO 2002; AHA 2017; FREPA 2020; Gerber et al. 2020; RSPCA Australia 2020). 
To achieve the required litter conditions, Australian meat chicken growers have been refining their litter, ventilation, and drinker management practices. Prior to undertaking this investigation, the authors were also aware that some Australian meat chicken growers were performing mechanical litter turning (otherwise known as litter tilling, stirring, or conditioning) during the grow-out period to break up cake and maintain litter in a friable state. It is suggested that litter turning may be defined as 'using machinery to break up caked litter, reduce the size of litter clumps with a cutting or pulverising action, mix wet with drier litter, and redistribute it at the back of the machine in a friable and homogenous surface layer'. These mechanisms improve friability, support litter drying processes and mix wet and dry litter together to deliver more uniform conditions that are simultaneously less dusty and with a lower peak moisture content to reduce susceptibility to caking.

In addition to managing litter during the grow-out, there has also been increasing interest in re-using litter for multiple grow-outs (Cockerill et al. 2020), as opposed to using new bedding for every growth cycle (McGahan et al. 2021). There has also been interest in sourcing alternative bedding materials (Watson and Wiedemann 2019), due to localised shortages in supplies of traditional bedding materials such as wood shavings, sawdust, rice hulls and straw due to events including bushfires and drought.

In this investigation, meat chicken farm owners, managers and staff (collectively known as 'growers') and poultry integrator company representatives were surveyed about their experiences regarding litter management practices and re-use. This was to gain a deeper understanding and improve the focus of research, development and extension activities (R,D\&E) on these topics. Industry surveys are very useful for informing researchers, policy makers and other stakeholders about industry-specific practices. A similar survey was undertaken in France by the Chambre d'Agriculture de Bretagne (The Chamber of Agriculture, Brittany) to gather information about their poultry growers' litter management practices, to understand the progression of these practices over the years, and to identify ways for researchers and extension staff to better assist their farmers (Dezat and Gohier-Austerlitz 2020).

Previous Australian chicken meat industry surveys have focused on litter availability, re-use, wet litter, litter amendments, management practices, farm design and housing characteristics (Runge et al. 2007; Dunlop et al. 2016; Moss and Selle 2016; Scott et al. 2017; Watson and Wiedemann 2019; Cockerill et al. 2020). While very informative, some of these surveys were focused on biosecurity or resource management and were conducted in specific growing regions rather than nationally, and were not directly focused on litter management or litter turning. Consequently, this survey was conducted with a more direct focus on experiences and methods relating to litter manage- ment and litter turning. The aim of the survey was to gather contemporary data, identify knowledge gaps, and improve the understanding of growers' current circumstances and litter management techniques, as litter management practices are constantly evolving.

Litter turning was a focus of this survey because it is not a globally conducted practice according to the limited literature and information available, but there has been some research and/or industry adoption of litter turning in Australia (Dunlop 2009; Pepper and Dunlop 2021), Japan (Taira et al. 2014), Europe (Estellés et al. 2011; Núñez Casas 2011; Villagrá et al. 2011; Dezat and Gohier-Austerlitz 2020), and in turkey production in Canada (van Staaveren et al. 2020) and the USA (Malone and Marsh Johnson 2017). There have also been some concerns expressed about the practice causing possible health and welfare concerns for the chickens, especially when it is performed at high liveweight density and because of the potential to cause surges in ammonia concentrations when the litter surface is turned over (Malone and Marsh Johnson 2017; Dezat and Gohier-Austerlitz 2020). The survey aimed to establish whether Australian meat chicken growers have relevant experiences or share the same concerns.

These survey results will be utilised in future R,D\&E activities to ensure research is informed by current industry practices, especially during the measurement of odour, ammonia and carbon dioxide during litter turning and other litter disturbance events, and to prioritise the selection of case studies that demonstrate best management practices concerning litter.

\section{Materials and methods}

\section{Survey design}

The industry survey was conducted online and consisted of 37 questions with a variety of open-ended, multiple-choice and ranking-scale questions. Some questions were dependent on others, whereby respondents were directed through different paths in the survey on the basis of one or multiple answers given. This enabled respondents to provide more detailed responses on specific topics while avoiding the need for them to answer questions about other topics, e.g. litter re-use, if they had previously stated that they had no relevant experience (Fig. 1).

Before distribution, the survey received approval from the funding body and a 'privacy collection notice' was provided at the start of the survey to ensure that participants were aware of how the information being collected would be used and retained. The survey link was then distributed by email to meat chicken growers and integrator staff across the six states in Australia by using industry representatives and grower networks. Responses were collected anonymously. 
* 12. Have you reused litter in the past?

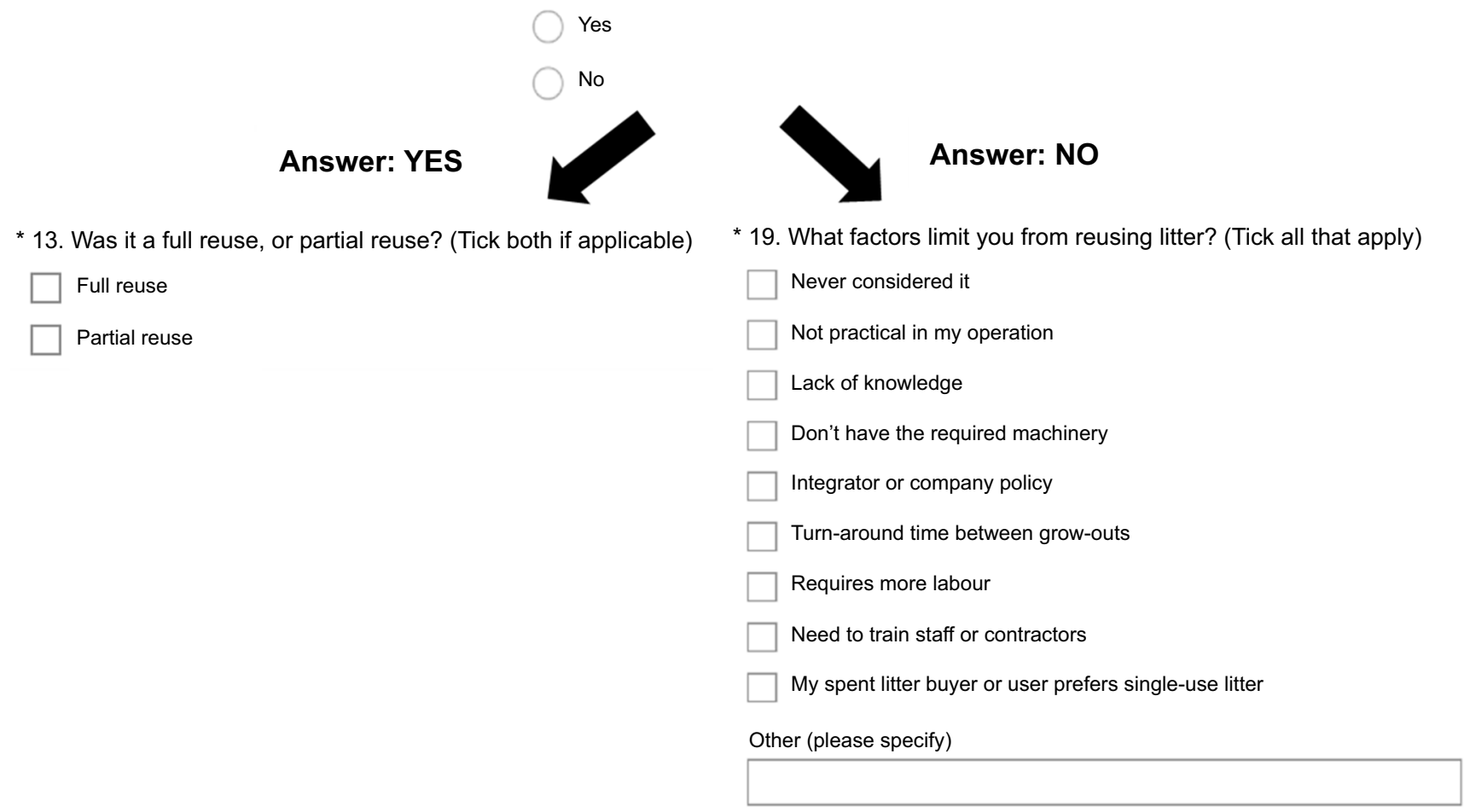

Fig. I. Example from the online survey when respondents were directed to questions.

The survey focused on farm characteristics including shed design, ventilation practices, preferred bedding materials and litter supply constraints, as these characteristics can affect the efficiency of litter management practices and may contribute to some litter problems. Questions about litter turning practices were included to collect data about the level of industry adoption, equipment used, motivations, limitations and perceptions about the potential risks associated with ammonia and odour concentrations. Litter re-use was another focus area and was a continuation of a previous industry survey by Dunlop et al. (2020), which focused on litter amendments. Litter re-use practices may affect and influence litter management techniques and the potential need for litter turning. The survey questions asked growers to describe their current litter re-use practices as well as their concerns, issues, and perceptions.

\section{Results and discussion}

\section{Survey population}

The survey received 84 responses from growers (98\% of survey responses) and integrator representatives (2\%) from the major growing regions and therefore reflected regional differences relating to climate, litter supply constraints, and local farming and husbandry methods. These regions were:
North Queensland, South East Queensland, Central Coast New South Wales (NSW), Inland NSW, South Coast Victoria, Inland Victoria, Western Australia, South Australia, and Tasmania (Fig. 2).

The sample pool represented growers from meat chicken farms across all growing regions; however, the largest number of respondents were from the South Coast of Victoria (40\%) and the lowest number were from Central Coast NSW ( $1 \%$ of respondents). There was relatively even representation from different farm sizes $(20-32 \%$ for each farm size category: <100 000, 100 000-250 000, 250000 400000 and $>400000$ chickens). Approximately $80 \%$ of the respondents were involved with conventional production (barn housing), and $21 \%$ involved with free range. (Note that some survey data results may not total $100 \%$ as some growers selected more than one option to reflect their farm, such as being involved with both conventional and freerange production, whereas others may have chosen not to respond at all.)

\section{Poultry house design and characteristics}

The design, construction and ventilation system in a poultry house contribute to the management of litter condition and moisture content. The survey results showed that most of the respondents had tunnel-ventilated poultry houses (90\%), followed by cross-ventilation (18\%) and natural ventilation 


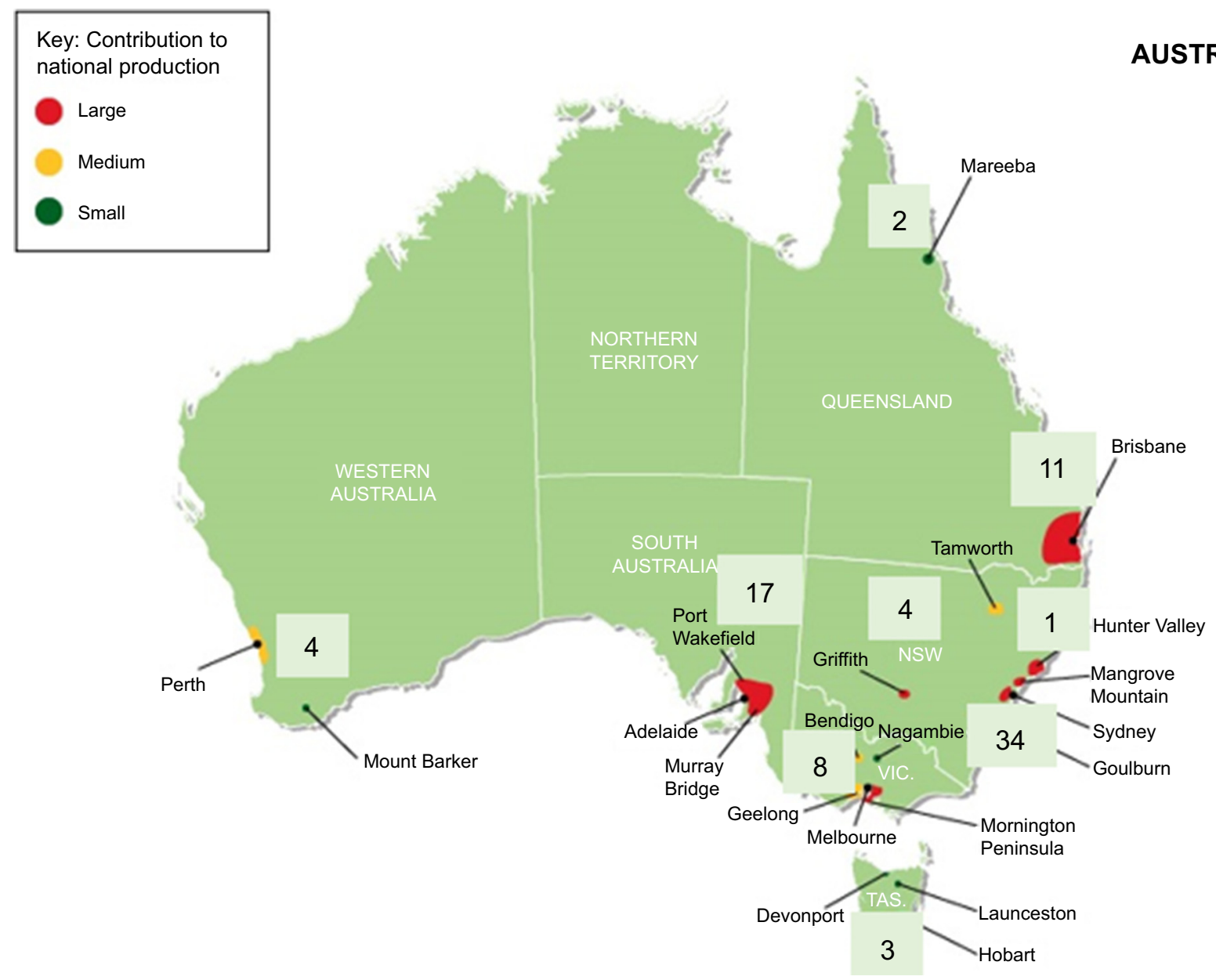

Fig. 2. Responses collected from each region [base map from ACMF (Australian Chicken Meat Federation Inc.) (202I)].

(15\%), with approximately $22 \%$ of the respondents having a combination of multiple ventilation types. Nearly a quarter of farms had in-shed air circulation or destratification fans $(23 \%)$ to assist with air mixing in the shed, and approximately $8 \%$ of farms had roof-mounted extraction fans.

Different types of heaters are available for use in meat chicken sheds, and it is suggested that the associated differences in heat distribution, litter heating (Campbell et al. 2017) and moisture production with various heaters is likely to have an impact on litter conditions. The majority of responses indicated that heating is provided by hot air/forced air/space heaters (94\%), followed by tube/radiant brooder heaters (4\%) and small brooder heaters (2\%).

Meat chicken sheds are built using a range of different designs, sizes, construction materials, floor construction and ventilation components due to individual or regional preferences and have evolved as building and ventilation technology has advanced. Most respondents had insulated solid walls, while others had curtains or concrete walls (Fig. 3). To control in-coming air through sidewall mounted mini-vents, most respondents used plastic vents (generally considered to be well sealed and promote directional air flow), while the remaining using metal vents (generally considered to seal less effectively and have less directional air flow). The tunnel inlets, which bring fresh air into the shed through the evaporative cooling pads during tunnel ventilation, were most commonly tilt panel tunnel inlets, followed by curtain tunnel inlets (Fig. 3).

It is suggested that shed characteristics affects shed tightness, the effectiveness of insulation and the control of in-coming fresh air, which are crucial to controlling and maintaining air movement, air quality, litter conditions, heating, and energy use within a shed (Collett 2012; Dunlop et al. 2016; Payne 1967; Jeppsson et al. 2021). The smoothness of the internal shed surfaces affects the consistency and efficiency of air flow within a shed. Most respondents stated they had exposed purlins or exposed roof trusses, with less than half having smooth-skin sheds (Fig. 3).

Last, most respondents had compacted earth floors, with about a quarter of respondents having concrete floors or cement treated road-base floors (Fig. 3). 


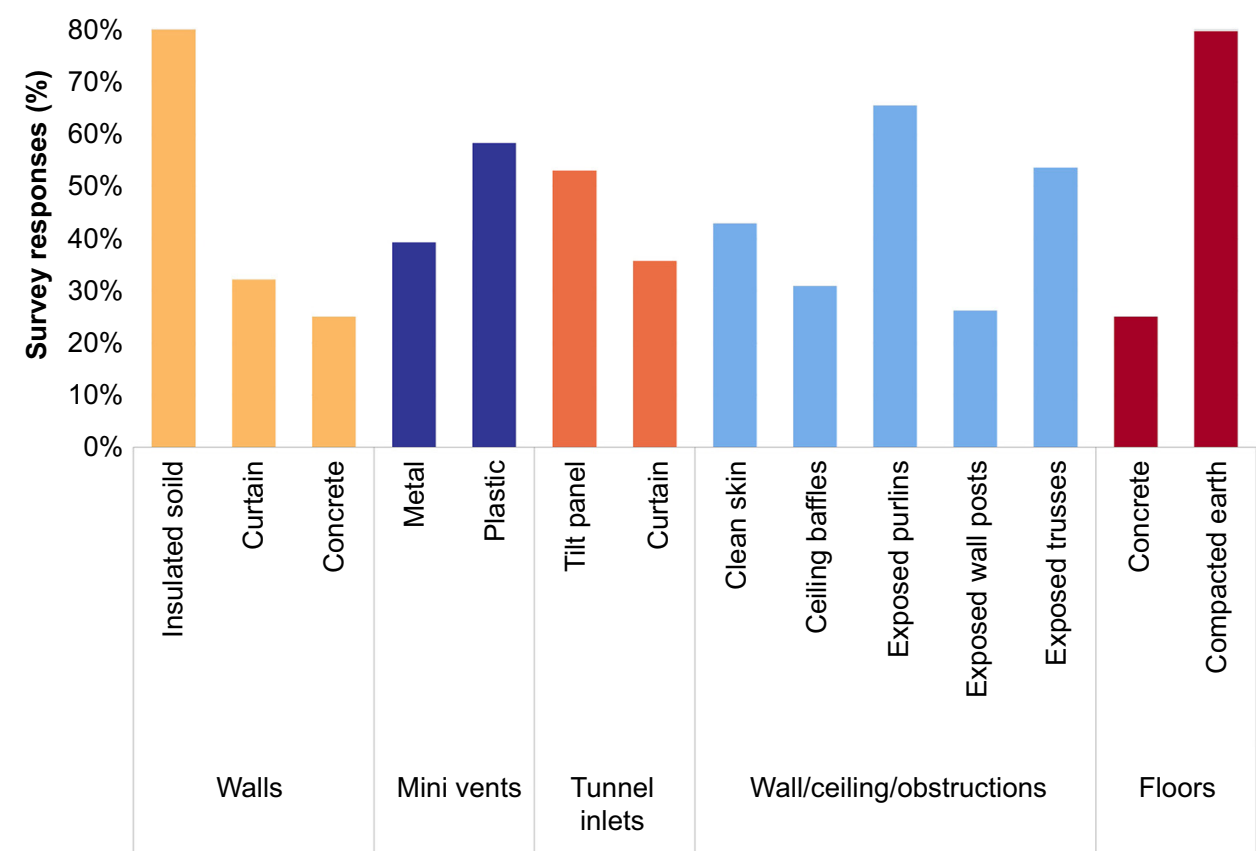

Fig. 3. Poultry shed design elements including wall, floor type and vent/air-inlet.

\section{Bedding materials}

The bedding material used by most of the respondents was softwood shavings (67\%), followed by hardwood shavings (46\%), straw (17\%) and rice hulls (13\%). Paper and peanut shells are not a commonly used bedding material (1\%), but may be considered as an alternative material if regular supply is limited. Regional differences in bedding materials were apparent, with South Australian respondents commonly using straw, whereas Queensland and Victorian growers use a combination of softwood or hardwood shavings or sawdust, and NSW respondents mainly use rice hulls. This trend of growing areas having a preferred bedding material was also observed to be similar in the previous Australian study (Watson and Wiedemann 2019).

Despite some bedding material shortages in recent years due to external influences such as drought and bushfires, only a few respondents stated that they regularly need to source alterative bedding. About one quarter of respondents need to occasionally source alternative bedding (less than a few batches per year), and about half of the respondents never need alternative bedding materials. Those who used rice hulls (13\%, primarily located in the Inland NSW region) commented that they were currently having difficulty sourcing the material.

\section{Litter re-use}

It was observed that 49 of 84 respondents (58\%) were willing to re-use litter, while $41 \%$ were not. Only 27 participants $(32 \%)$ of the 84 have re-used litter in the past. Those who would consider re-using litter where mainly located in the
South East Queensland region, which was not surprising considering that $41 \%$ of these respondents already regularly re-use litter.

Most survey respondents have never re-used litter (67\%). Of those who have re-used litter (at least once), 33\% practiced full litter re-use and $81 \%$ practiced partial re-use. The most common deciding factors for litter re-use included integrator or company policy (48\%), cost of new bedding (37\%), availability of new bedding materials (37\%), and turn-around time between grow-outs (29\%). For those who do not re-use litter, limiting factors included not having the required equipment (26\%) and lack of knowledge (25\%).

To ensure that litter re-use is effective, and to reduce potential risks associated with pathogens and ammonia, growers tend to windrow or heap litter between batches (70\%) and increase ventilation during brooding (55\%).

Despite survey respondents indicating that litter re-use provides benefits such as increased litter depth (56\%) and reduced bedding costs (63\%), litter re-use was also recognised as having some potential challenges or negative impacts if it is not effectively managed. Respondents stated that the greatest challenges were increased ammonia levels (93\%) and darkling beetle management (37\%). 'Build-up' of ammonia with re-used litter was the greatest concern for respondents, with $57 \%$ of respondents reporting that they were 'extremely concerned' about it (Fig. 4). This expressed level of concern for ammonia suggests that there is a need for future research or training regarding ammonia management options. There were concerns around litter beetle management that potentially relate to increases in beetle populations from litter re-use (Lambkin et al. 2007) and 


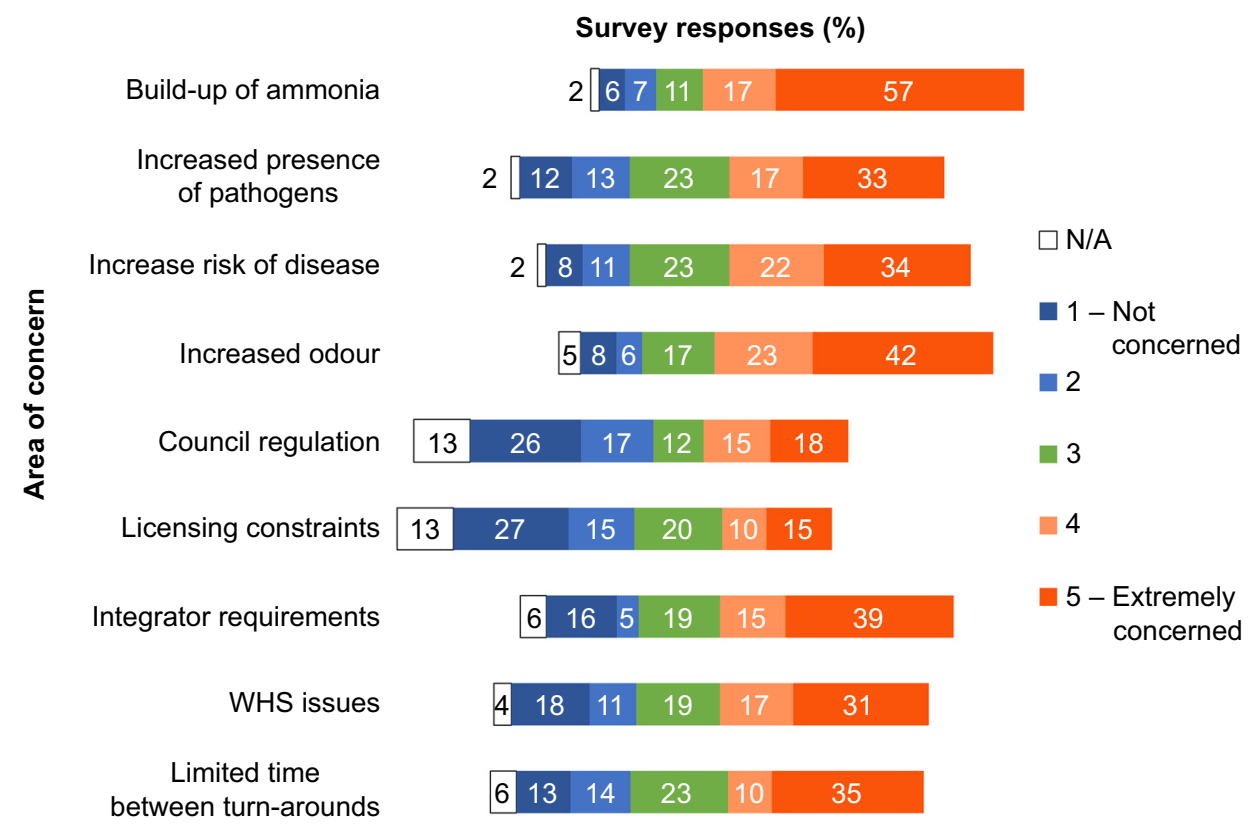

Fig. 4. Stacked graph displaying the level of concerns relating to re-using litter. WHS, work health and safety.

the additional challenges associated with applying beetle control strategies with litter remaining in the shed.

\section{Litter turning}

In total, $89 \%$ of growers have adopted the practice of litter turning to assist in maintaining dry and friable litter in addition to routine management of ventilation, heaters and drinkers. Only a few (9\%) responded that they rely solely on other management practices that do not include litter turning, such as top dressing.

Overseas experiences with litter turning suggest that caution is required during and after litter turning because of the potential for a surge in ammonia (Malone and Marsh Johnson 2017; Dezat and Gohier-Austerlitz 2020). These experiences were generally echoed by Australian growers, but their greatest concern was for the welfare of the chickens while turning litter at times when liveweight density is approaching its maximum. This concern was reinforced by the majority of respondents saying that they are unable to turn the litter between 27 and 34 days (Fig. 5), which is when the density is typically at its greatest (because it precedes a thin-out or removal of a portion of the chickens from the shed for slaughter between 31 and 35 days). There were no clear trends with inability to perform litter turning relating to equipment type, size or farm size. More information will be required to more deeply understand the concerns and perceptions expressed by the growers and integrators.

The most common types of machinery used for litter turning included rotary hoes $(51 \%)$ and purposely built

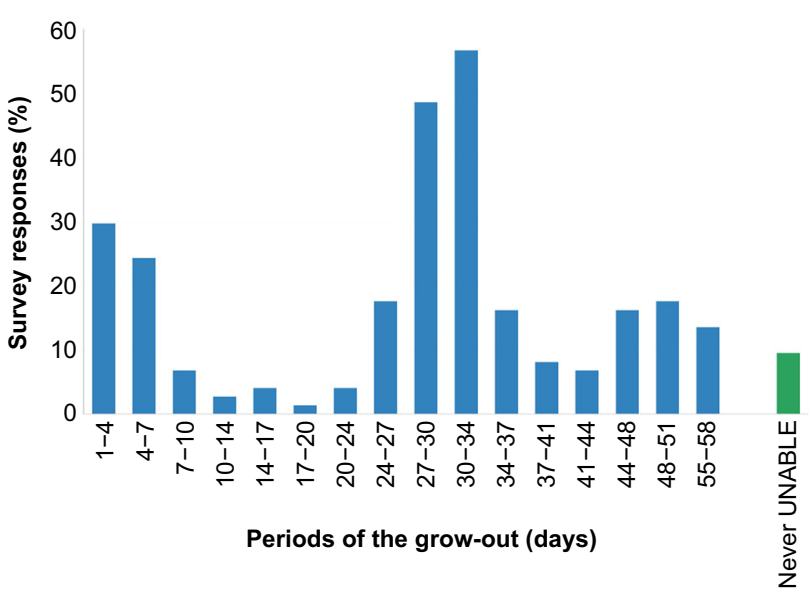

Fig. 5. Survey response of times when growers are UNABLE to perform litter turning.

machinery (32\%, e.g. Frantumix). The majority of respondents have small tractor-driven attachments (up to 1.5-1.8 m wide) $(61 \%)$, followed by larger-size tractor-driven attachments (wider than 1.5-1.8 m) (28\%), and walk-behind machines (6\%).

Litter turning is performed as either a scheduled practice or in response to caking. Growers in South East Queensland most frequently responded that they schedule litter turning, whereas growers in the Victoria Coast region tended to respond that they conducted litter turning in response to caking. Caking was reported to mostly occur under drinker lines (84\%), but the respondents preferred to turn the litter 


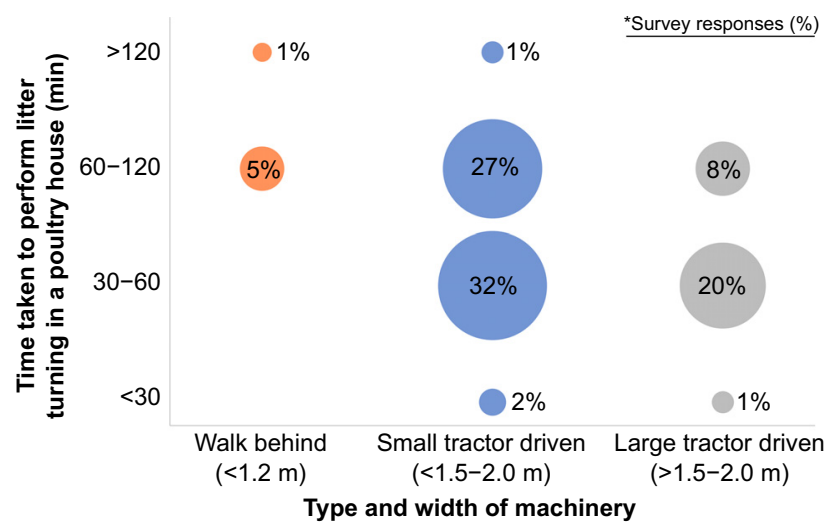

Fig. 6. Time taken for growers to perform litter turning depending on the machinery size.

across the whole shed floor (78\%). Responses indicated that litter turning operations commonly occurred weekly (64\%), around mid-morning (80\%), or sometimes noon (46\%), and took $0.5-1 \mathrm{~h}(52 \%)$ to $1-2 \mathrm{~h}(40 \%)$ per shed. The size of the machinery influenced the length of time taken to turn litter in a shed (Fig. 6), with larger tractor-driven machines tending to perform the operation more quickly than smaller walk-behind machines. Despite the extra time required, respondents with walk-behind machines reported that they were convenient for targeting small areas of caked or moist litter.

\section{Additional comments by respondents about litter management}

Additional comments were provided by respondents on other approaches to keeping litter friable. These included being proactive and strategic with the following:

- appropriate and effective ventilation;

- drinker height and maintenance;

- circulation fans;

- hand-raking or using a small rotary hoe to target specific areas (e.g. under drinker lines);

- top dressing - removing wet litter and replacing with fresh material;

- good feed quality and contents;

- correct use of migration barriers to improve the uniformity of liveweight density throughout the poultry house;

- monitoring and managing humidity within the sheds;

- maintaining the quality of sheds and keeping equipment in good condition.

Combining these shed management practices supports the concept of applying a whole-system approach to keeping litter 'dry and friable'. Maintaining friability and the ideal moisture content requires pro-active, effective, and appropriate ventilation, supplemental heating, drinker management and nutrition. 'Working' the litter, either by chicken activity or mechanical litter turning, is an additional management practice that further promotes aerobic conditions, accelerates moisture loss and improves friability (Bernhart and Fasina 2009; Lister 2009; Dunlop et al. 2016). It is suggested that keeping the litter working enables chickens to more readily break-up and work fresh excreta into the litter to prevent the formation of a crusted/caked litter surface.

\section{Conclusions}

This industry survey has captured a snapshot of how meat chicken growers across Australia currently manage litter, with a focus on litter re-use and litter turning. Eighty-four survey responses were received from all major growing regions across Australia and represented free-range and conventional production systems. The survey showed that litter re-use is limited, but litter turning is a widespread practice. Litter turning is used to reduce the occurrence of caked litter and to keep litter 'working'. Comments from the survey indicated that litter turning alone does not achieve dry and friable litter, and that proactive ventilation, heater and drinker management are essential. Growers also explained that litter turning is not without its challenges, and can potentially contribute to spikes of dust, ammonia and/or odour, as well as being difficult to carry out when there is high live-weight density.

In conclusion, these survey results will be invaluable for ensuring that future R,D\&E activities reflect industry practices, especially in the assessment of the chicken production environment and refinement of litter management practices.

\section{References}

ACMF (Australian Chicken Meat Federation lnc.) (2021) Structure of the industry. Available at https://www.chicken.org.au/structure-of-theindustry/. [Verified 19 March 2021]

AHA (2017) Australian animal welfare standards and guidelines for poultry - version: proposed draft - public consultation Nov 2017. (Animal Health Australia: Braddon, ACT, Australia). Available at http://www.animalwelfarestandards.net.au/poultry/. [Verified 20 July 2021]

Bernhart M, Fasina OO (2009) Moisture effect on the storage, handling and flow properties of poultry litter. Waste Management 29, 1392-1398. doi:10.1016/j.wasman.2008.09.005

Campbell J, Brothers D, Donald J (2017) Poultry house ventilation guide: a practical guide for managing risk in poultry production. (American Association of Avian Pathologists: Jacksonville, FL, USA). Available at https://www.aaap.info/practical-guide-2nd-edition. [Verified 20 July 2021]

Cockerill SA, Gerber PF, Walkden-Brown SW, Dunlop MW (2020) Suitability of litter amendments for the Australian chicken meat industry. Animal Production Science 60, 1469-1481. doi:10.1071/ AN19587

Collett SR (2012) Nutrition and wet litter problems in poultry. Animal Feed Science and Technology 173, 65-75. doi:10.1016/j.anifeedsci. 2011.12 .013

CSIRO (2002) 'Primary industries report series - model code of practrice for the welfare of animals: domestic poultry.', 4th edn. (CSIRO Publishing: Melbourne, Vic., Australia). Available at https://www. 
publish.csiro.au/ebook/download/pdf/3451. [Accessed 24 November 2020]

Dezat E, Gohier-Austerlitz D (2020) Gestion des litieres et du fumier chez les aviculteurs Bretons - Résultats d'une enquête réalisée auprès des éleveurs de poulets et dindes standard [Management of litters and manure in Breton poultry farmers results of a survey of standard chicken and turkey farmers]. Available at http://www.bretagne.synagri.com/ ca1/synagri.nsf/pages/gestion-des-litieres-en-aviculture. [Verified 20 July 2021]

Dunlop MW (2009) Control of odour and dust from chicken sheds - review of 'add-on' technologies. (RIRDC: Canberra, ACT, Australia). Available at https://www.agrifutures.com.au/product/control-of-odour-anddust-from-chicken-sheds-review-of-add-on-technologies/. [Verified March 2009]

Dunlop MW, Moss AF, Groves PJ, Wilkinson SJ, Stuetz RM, Selle PH (2016) The multidimensional causal factors of 'wet litter' in chickenmeat production. Science of the Total Environment 562, 766-776. doi:10.1016/j.scitotenv.2016.03.147

Dunlop M, Cockerill S, Gerber P, Walkden-Brown S, Chinivasagam N (2020) Suitability of litter amendments for the Australian chicken meat industry. (AgriFutures Australia: Canberra, ACT, Australia). Available at https://www.agrifutures.com.au/product/suitabilityof-litter-amendments-for-the-australian-chicken-meat-industry/. [Verified March 2020]

Estellés F, Cambra-López M, Adell E, Borrás M, Jiménez-Belenguer AI, Vazquez S, Olivas I, Villagrá A, Calvet S (2011) Volteo de la cama durante el ciclo productivo de pollos de engorde. Parte II: Evaluación ambiental [Litter turning during the production cycle of broiler chickens. Part II: Environmental Assessment]. In 'VI Congreso Iberico de Agrolngenieria (VI Iberian Agro-Engineers Congress), Universidade de Evora, Portugal, 5-7 September 2011'.

FREPA (2020) FREPA Chicken meat standard. Available at https://frepa. com.au/wp-content/uploads/2020/09/FREPA-Chicken-Meat-StandardSept-2020.pdf. [Verified 24 November 2020]

Gerber PF, Gould N, McGahan E (2020) Potential contaminants and hazards in alternative chicken bedding materials and proposed guidance levels: a review. Poultry Science 99, 6664-6684. doi:10.1016/j.psj.2020.09.047

Jeppsson K-H, Olsson A-C, Nasirahmadi A (2021) Increased air velocity in the lying area improves pen hygiene and reduces ammonia emissions from houses with partly slatted pens for growing/finishing pigs. Livestock Science 251, 104607. doi:10.1016/j.livsci.2021.104607

Lambkin TA, Kopittke RA, Rice SJ, Bartlett JS, Zalucki MP (2007) Distributions of lesser mealworm (Coleoptera: Tenebrionidae) in litter of a compacted earth floor broiler house in subtropical Queensland, Australia. Journal of Economic Entomology 100, 1136-1146. doi:10.1093/jee/100.4.1136

Lister SA (2009) Effects of litter moisture on performance, health and welfare. In 'Beekbergen'. pp. 33-39. (World Poultry Science Association (WPSA))

Malone G, Marsh Johnson T (2017) Litter management for the 21st century: a practical guide for managing risk in poultry production. (Ed RL Owen) (American Association of Avian Pathologists:
Jacksonville, FL, USA). Available at https://www.aaap.info/ practical-guide-2nd-edition. [Verified 20 July 2021]

McGahan E, Gould N, Dunlop M (2021) Best practice litter management manual for Australian meat chicken farms: covering fresh, in-shed, reuse and spent litter management. (AgriFutures Australia). Available at https://www.agrifutures.com.au/product/final-reportbest-practice-litter-management-manual-for-australian-meat-chickenfarms/ [Verified 14 July 2021]

Moss AF, Selle PH (2016) Causal factors of 'wet litter' in chicken-meat production. Available at https://www.agrifutures.com.au/product/ causal-factors-of-wet-litter-in-chicken-meat-production/. [Verified 17 August 2020]

Núñez Casas JJ (2011) 'Litter aeration during the rearing cycle of broilers: productive and welfare implications.' (Universitario en Producción Animal)

Payne CG (1967) Factors influencing environmental temperature and humidity in intensive broiler houses during the post-brooding period. British Poultry Science 8, 101-118. doi:10.1080/00071666708 415656

Pepper C-M, Dunlop MW (2021) Review of litter turning during a growout as a litter management practice to achieve dry and friable litter in poultry production. Poultry Science 100, 101071. doi:10.1016/j.psj. 2021.101071

RSPCA Australia (2020) RSPCA Approved farming scheme standards: meat chickens (March 2020). (RSPCA Australia: Canberra, ACT, Australia). Available at https://rspcaapproved.org.au/join/\#standards. [Verified 24 April 2020]

Runge GA, Blackall PJ, Casey KD (2007) Chicken litter: issues associated with sourcing and use. (RIRDC: Canberra, ACT, Australia). Available at https://www.agrifutures.com.au/product/chicken-litter-issuesassociated-with-sourcing-and-use/. [Verified 16 January 2018]

Scott AB, Singh M, Toribio J-A, Hernandez-Jover M, Barnes B, Glass K, Moloney B, Lee A, Groves P (2017) Comparisons of management practices and farm design on Australian commercial layer and meat chicken farms: cage, barn and free range. PLOS ONE 12, e0188505.

Taira K, Nagai T, Obi T, Takase K (2014) Effect of litter moisture on the development of footpad dermatitis in broiler chickens. Journal of Veterinary Medical Science 76, 583-586. doi:10.1292/jvms.13-0321

van Staaveren N, Leishman EM, Adams SM, Wood BJ, HarlanderMatauschek A, Baes CF (2020) Housing and management of turkey flocks in Canada. Animals 10, 1159.

Villagrá A, Nunez JJ, Olivas I, Borrás M, Calvet S, Cambra-López M, Adell E, Estellés F (2011) Volteo de la cama durante el ciclo productivo de pollos de engorde. Parte I: implicaciones productivas (Litter turning during the production cycle of broiler chickens. Part I: productive implications). In 'VI Congreso Iberico de Agrolngenieria [VI Iberian Agro-Engineers Congress], Universidade de Evora, Portugal, 5-7 September 2011'.

Watson K, Wiedemann SG (2019) Review of fresh litter supply, management and spent litter utilisation. Vol. Project No. PRJ-010655. (Agrifutures Australia: Canberra, ACT, Australia). Available at https://www.agrifutures.com.au/product/review-of-fresh-litter-supplymanagement-and-spent-litter-utilisation/. [Verified 6 August 2019]

Data availability. The data that support this study cannot be publicly shared due to ethical or privacy reasons and may be shared upon reasonable request to the corresponding author if appropriate.

Conflicts of interest. The authors declare no conflicts of interest for this paper.

Declaration of funding. This research has been supported by funding from the Agrifutures Australia Chicken Meat Program (PRJ-0II502), and the Department of Agriculture and Fisheries, Queensland Government.

Acknowledgements. The authors thank the growers and integrators who participated in this survey, as well as David Mayer and Kerri Chandra for assisting with the data analysis of the survey results, and chicken meat industry representatives and consultants who provided feedback on the survey questions and distributed this survey to their networks. Thanks go to Elodie Dezat and Delphine Gohier-Austerlitz from Chambre d'Agriculture de Bretagne who recently published their grower survey data in a short summary, as this encouraged us to the do the same with our survey results.

Author affiliation

ADepartment of Agriculture and Fisheries, Queensland Government, 203 Tor Street, Toowoomba, QId 4350, Australia. 